\title{
PRIMARY ABDOMINAL PREGNANCY
}

\author{
Poonam Kalburgi', Sanjaykumar Patil ${ }^{2}$
}

1 Postgraduate Student, Department of Obstetrics and Gynaecology, Krishna Institute of Medical Sciences, Karad, Maharashtra, India. 2Professor, Department of Obstetrics and Gynaecology, Krishna Institute of Medical Sciences, Karad, Maharashtra, India.

HOW TO CITE THIS ARTICLE: Kalburgi P, Patil S. Primary abdominal pregnancy. J. Evolution Med. Dent. Sci. 2019;8(25):2031-2032, DOI: $10.14260 /$ jemds/2019/447

\section{PRESENTATION OF CASE}

A 25-years-old patient P2L2 married since 7 years with previous two LSCS came to OPD with chief c/o amenorrhoea since 4 months with nausea and vomiting with some hard mass felt in left side of abdomen since two weeks with pain in abdomen on-off since two weeks. She had regular menstrual cycles of 28-32 days with moderate flow.

This was spontaneous conception. Without undergoing any ultrasound examination, she had undergone D\&C 4 weeks back. 3 weeks after D\&C due to persistent nausea and pain in abdomen she had checked her UPT which was positive.

Abdominal pregnancy is a potentially life-threatening form of ectopic gestation with incidence of $1 \%$ of all ectopic pregnancies. Very rarely it may reach advanced gestation ${ }^{(1)}$ with viable foetal outcome. Most of them are terminated earlier due to poor foetal outcome with higher chances of maternal morbidity and mortality. A high degree of suspicion for diagnosis and its timely management is of utmost importance in terms of saving life of a patients.

\section{CLINICAL DIAGNOSIS}

On examination she was conscious, oriented with pulse rate of 98 per minute. BP was $110 / 70 \mathrm{mmHg}$. Mild tenderness was present in the left iliac and lumbar regions. A mass was felt arising from pelvis and extending up to left lumbar region of around 20 weeks size and it was non mobile. On per speculum examination, cervix and vagina were normal with no bleeding or any discharge. On bimanual per vaginal examination, uterus was bulky $\sim 10$ weeks with tenderness in left fornix.

Transabdominal USG revealed

- $\quad$ e/o bulky uterus deviated to right side.

- No e/o intrauterine gestational sac.

- e/o left adnexal gestational sac implanted on pelvic peritoneum with live foetus of $\sim 19$ weeks.

- Absence of myometrial tissue around gestational sac.

- Placenta located on superior and lateral aspect of gestational sac.

Baby weight 289 gms with AFI 13-14 cm.

\section{DIFFERENTIAL DIAGNOSIS}

1. Ectopic pregnancy

2. Left sided ovarian cyst

3. Pelvic tumour

4. Any GI tract neoplasm (Rare)

'Financial or Other Competing Interest': None. Submission 11-04-2019, Peer Review 08-06-2019,

Acceptance 14-06-2019, Published 24-06-2019.

Corresponding Author:

Dr. Poonam Kalburgi,

A-17, Yogashree, Rukmini Nagar,

Part 2, Karad, Maharashtra, India.

E-mail:kalburgipoonam28@gmail.com

DOI: $10.14260 /$ jemds $/ 2019 / 447$

\section{DISCUSSION OF MANAGEMENT}

Routine investigation revealed $\mathrm{Hb} 14 \mathrm{gm} \%$ platelets 2.75 lakhs/cumm. She underwent exploratory laparotomy under GA Intraoperatively. No hemoperitoneum or clots were found. Uterus was bulky 10 Weeks size and Deviated to Right SideA foetus en-sac along with placenta found attached to peritoneum overlying pouch of Douglas. Placenta was partially adherent to loops of small intestine as well which was left undisturbed. Left sided fallopian tube and ovary was adherent to each other and to placenta; hence removed. Right sided fallopian tube and ovary were normal and tubal ligation done on that side. There was no active bleeding from implantation site. There were no adhesions in abdominal or pelvic cavity. Total blood loss was around $250 \mathrm{cc}$. Post-operative period was uneventful. And patient was discharged on $7^{\text {th }}$ post-operative day.
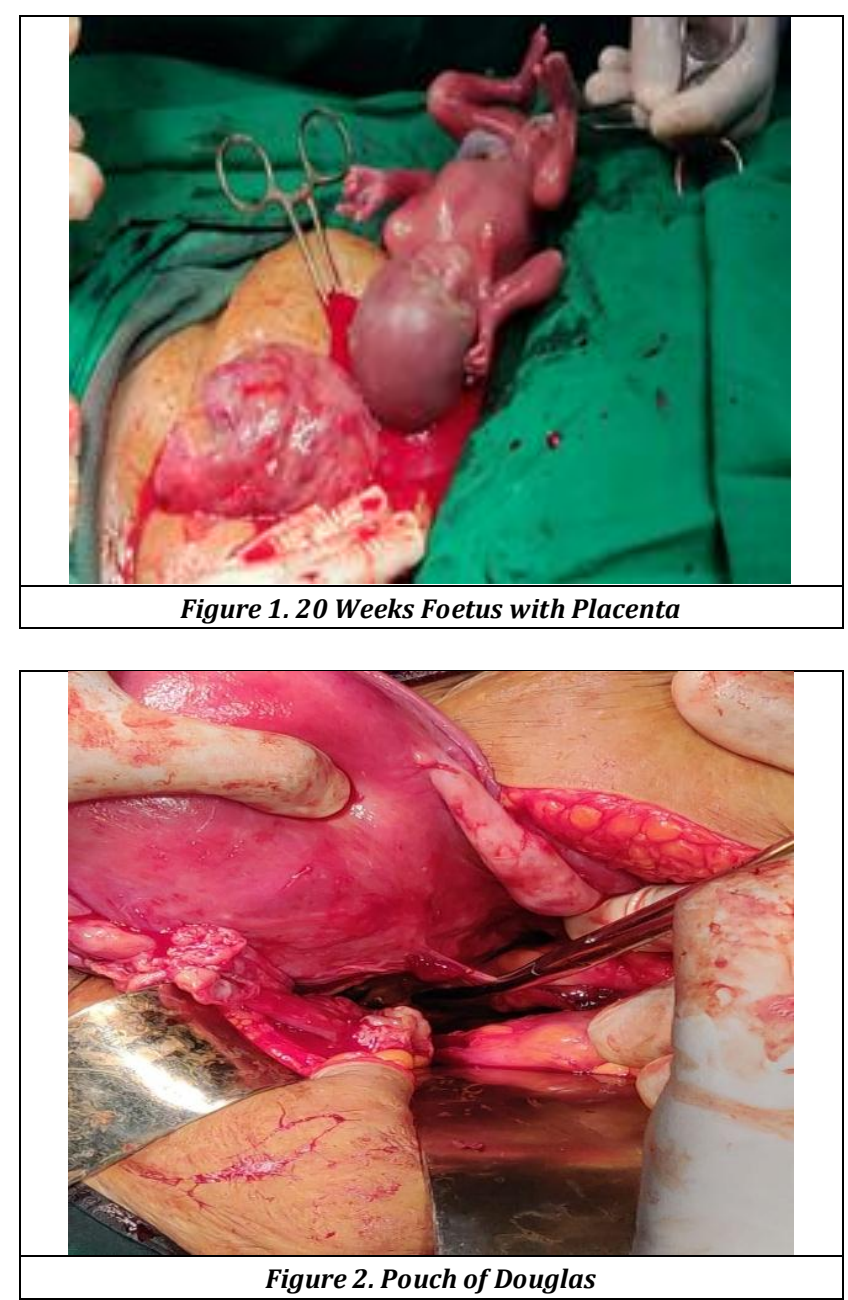

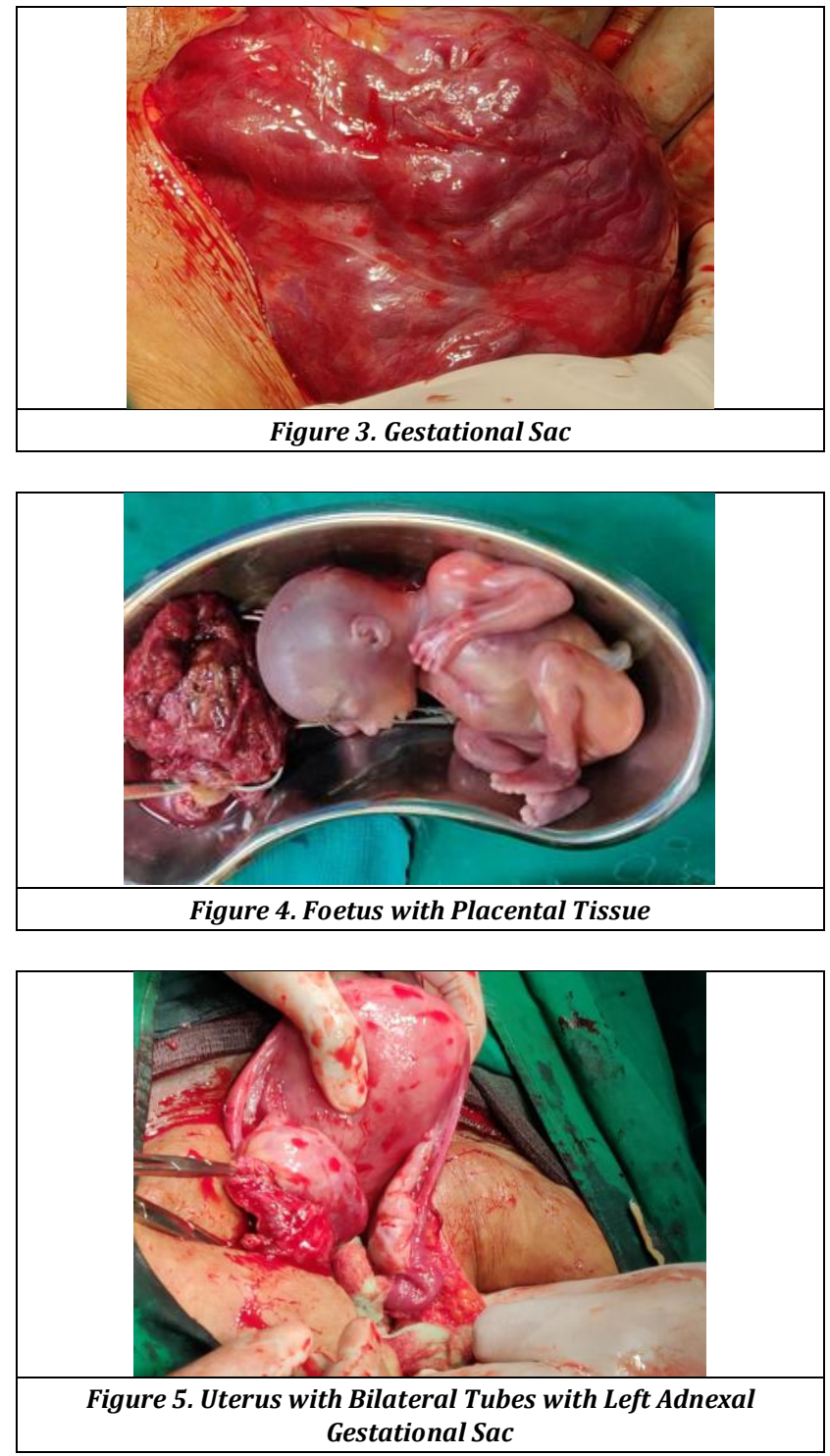

\section{PATHOLOGICAL DISCUSSION}

About 1 to $2 \%$ of all pregnancies are ectopic pregnancies and the most common site being fallopian tube. Incidence of abdominal pregnancy is $1 \%{ }^{(2)}$. Abdominal pregnancy refers to a pregnancy that has implanted in peritoneal cavity outside the uterus and fallopian tubes. Placenta can be implanted to any of the abdominal organs, pelvic vessels or can be separate from site of implantation. Multiparity, tubal damage secondary to PID, endometriosis are risk factors for abdominal pregnancies.

According to STUDIFORDs(2) criteria primary abdominal pregnancy is said to be present when tubes and ovaries are normal, when there is absence of uteroperitoneal fistula and there is attachment exclusively to peritoneal surface early enough in gestation to eliminate the likelihood of secondary implantation from primary site.

Non contrast MRI is sensitive, specific \& accurate method for evaluating ectopic pregnancy.(3) Abnormal trends serial HCG values which is seen in tubal ectopic are usually not seen in abdominal ectopic. Other differential diagnosis(4) includes ectopic pregnancy in other locations, intra uterine pregnancy in rudimentary uterine horn, uterine rupture.

In contrast to tubal ectopic pregnancy, primary methotrexate ${ }^{(3)}$ therapy has high risk of failure due to more advanced gestational age at which these pregnancies are diagnosed. Expectant management to attain foetal maturity has been tried in few cases. Life threatening maternal haemorrhage may occur during placental separation. So, ligation of umbilical cord and leaving placenta in situ is one option. Adequate blood and blood products should always be kept ready. Placental mass may take years to absorb and HCG may take few months to decline. Regular follow up is required for early diagnosis of inflammatory changes related to necrotic placenta like intestinal or ureteral obstruction, fistula, abscess or sepsis.

Common malformation in foetus includes hypoplastic limbs, joint abnormalities, cranial asymmetry. LITHOPEDION (stone child) ${ }^{(4)}$ may result from dead and calcified abdominal pregnancy.

\section{FINAL DIAGNOSIS}

Primary Abdominal Pregnancy

From this case it can be inferred that antenatal ultrasound should be always done before MTP to confirm the site of pregnancy. High index of suspicion is required to diagnose abdominal pregnancy when patient's vitals are stable. Timely management is key to save life. Written informed consent was taken for publication of this case report and related images.

\section{REFERENCES}

[1] Onan MA, Turp AB, Saltik A, et al. Primary omental pregnancy: case report. Human Reproduction 2005;20(3):807-9.

[2] Cunningham FG. Williams text book of obstetrics. 25th edn. New York, USA: McGraw-Hill Publication 2018: p. 371-3.

[3] Jurkovic D, Wilkinson H. Diagnosis and management of ectopic pregnancy. British Medical Journal 2011;342:d3397.

[4] Mass DA, Slabber CF. Diagnosis and treatment of advanced extra uterine pregnancy. S Afr Med J 1975;49(48):2007-10. 